\title{
Sinergias entre pedagogía sistémica y método etnográfico en el trabajo de campo
}

Recibido: 28 de marzo de 2019 / Revisado: 2 de abril de 2019

Aceptado: 4 de mayo de 2019 / Publicado: 22 de julio de 2019

AURORA ARDIT-GIMÉNEZ

Universitat Jaume I, España al053736@uji.es

\section{RESUMEN}

Se describe cómo se llevó a cabo la entrada al campo de investigación desde acciones y miradas que aportan la pedagogía sistémica y la etnografía. Tras la demanda recibida del claustro para realizar una formación sobre pedagogía sistémica en el Centro Rural Agrupado Peña Escabia, situado en la provincia de Castellón; se da comienzo a una investigación en la que participan el claustro, familias, personal no docente, y alumnado. A partir de la observación participante y la consecuente producción de datos, se detalla cómo se desarrollaron los siguientes 5 pasos desde ambas miradas:

La demanda y posicionamiento.

La fase 1 de negociación: primera visita al campo.

La fase 2 de negociación: la presentación en la comunidad.

La fase 3 de negociación: el consentimiento informado. Y final del proceso.

Se concluye con algunas sinergias observadas. Por ejemplo, se observa, de un lado, la mirada de delicadeza y el posicionamiento que aporta la pedagogía sistémica para encontrar como investigadores el lugar correspondiente en el campo de investigación, y de otro, la forma cuidadosa y respetuosa, alejada de la intromisión, que se describe desde la etnografía.

Palabras Clave: Etnografía, Estudio de campo, Relaciones Interpersonales, Teoría de Sistemas

\section{ABSTRACT}

Synergies between systemic pedagogy and ethnographic method in fieldwork

This excerpt explores the initiation and development of systemic pedagogy and ethnographic method, from an early vision to an applied practice. After an initial training in systemic pedagogy is requested by staff, the "Centro Rural Agrupado Peña Escabia", centrally located in the province of Castellón; launches a program designed to integrate family, staff, non-teaching staff, and students. From participant observation, subsequently collected data, and thorough reflection, the following five steps were curated and represent the perspectives of both systematic pedagogy and ethnographic method:

Demand and positioning.

Phase 1 of negotiation: first visit to the field.

Phase 2 of negotiation: presentation to the community.

Phase 3 of negotiation: informed consent.

And the final phase.

The article concludes with a look into observed synergies throughout the program, such as ways to improve physical health, boundary setting, and ways to match individuals to specific areas of research or the study.

We conclude with some of the synergies observed. For example, on one hand, systemic pedagogy provides a soft look and a place inside the research field, and on the other, ethnography describes a careful and respectful way, far from the intrusion.

Keywords: Ethnography, Field Studies, Interpersonal Relationship, Systems Approach. 


\section{Introducción}

Se encuentra una cantidad de artículos sobre la pedagogía sistémica en cuanto a los órdenes, dimensiones, creación de vínculos, organización del centro... Otros detallan experiencias de cómo se han trasladado estas teorías al aula (Olvera y Bolzmann, 2007; Parellada, 2006; Pastor, 2006; Traveset, 2007).

En España, se han realizado diversas investigaciones científicas acerca de la aplicación de la pedagogía sistémica en entornos educativos mediante estudio de casos, intervención social con familias, supervisión clínica (Gómez y Pérez, 2005; Gómez, 2007; Sánchez, 2013). Sin embargo, existe un vacío de investigación cuando se trata de situar a la pedagogía sistémica como una posible aportación a los métodos de investigación. En este caso, se pretende considerar a la pedagogía sistémica como un posible complemento del método etnográfico.

El objetivo del artículo se centra en describir el proceso de entrada al campo desde la pedagogía sistémica y el método etnográfico y analizar los puntos de convergencia entre ambos. Podría servir de apoyo a jóvenes investigadores que se planteen metodologías transdisciplinares en sus proyectos de investigación, sobre todo en cómo iniciar la entrada al campo. Observaremos, si la pedagogía sistémica puede considerarse además de un recurso pedagógico de contenido, un recurso que complemente a la investigación científica para enfatizar cuestiones éticas de acercamiento al campo de investigación.

Esta entrada al campo se engloba dentro de un proyecto de investigación de tesis doctoral que tiene como objetivo dar respuesta a la siguiente hipótesis: "La inclusión educativa y la pedagogía sistémica se complementan para promover una mejora de la convivencia en la comunidad escolar (claustro-familiaalumnado-personal no docente) y fortalecer vínculos de reconocimiento y dignidad hacia sus territorios".

Realizaremos una breve aproximación teórica para observar si existen puntos de convergencia que puedan acercarnos a la mirada etnográfica.

\section{Marco teórico}

\subsection{Orígenes de la Pedagogía Sistémica}

La pedagogía sistémica nace de la teoría de los órdenes del amor, descritos por Bert Hellinger a finales del siglo XX, tras años de investigación acerca de cómo estos órdenes operaban en el ser humano (Hellinger, 2001).

Marianne Franke-Griscksch y Angélica Olvera llevaron a cabo dichos órdenes al ámbito de la edu- 
cación. Angélica Olvera y Alfonso Malpica, decidieron acuñarle con el nombre de Pedagogía Sistémica CUDECC (Traveset, 2007). A partir de ahí, aproximadamente en 2003, comenzaron a expandirse las formaciones por Latinoamérica, Alemania y España. Aunque seguramente existieron más personas que trasladarían los órdenes del amor a la escuela, sin embargo, al no sistematizar sus experiencias, no existe documentación al respecto, no obstante desde aquí, reconocemos a quienes pudieron quedar olvidadas.

\subsection{Pilares que la sostienen}

La pedagogía sistémica se basa en un enfoque sistémico, fenomenológico, transgeneracional (Parellada, 2006; Olvera y Scheneider, 2007; Sánchez, 2013) y por tanto, emocional, como aspecto intrínseco al ser humano (Traveset, 2012). Desde este paradigma pedagógico, cuando hagamos referencia a la mirada sistémica, la entenderemos como una nueva mirada amplia que engloba lo sistémico, transgeneracional, fenomenológico y emocional.

Sistémico, desde la mirada amplia que contempla el todo de un sistema, incluidos aquellos límites y entornos con los que establece conexión. De alguna manera estos influyen y llevan a transformaciones y viceversa. Cada sistema forma parte de otro sistema mayor quedando conectados (Bronfenbrenner, 1987; Bertalanfyy, 1989; Maturana y Varela, 2003). Forma parte de un sistema todo aquello que también forma parte del ser humano, sus pensamientos, emociones, su cuerpo físico, su alma, sus acciones, su historia, su familia, los contextos y seres con los que interactúa, su memoria personal y colectiva...

Desde una comprensión de sistema desde lo antagónico para su existencia, pues ambos opuestos se retroalimentan (Luhmann, 1998; Morin, 2006); y desde las interconexiones de los sistemas que influyen en tiempo y espacio, nos preparamos para observar el sistema familiar y escolar que siempre será mayor a la suma de sus partes (Ander-Egg, 1996; González, 2009).

Fenomenológico porque se centra en la comprensión de la realidad, en la descripción del fenómeno de la manera más cercana posible, sin juicios o valores que puedan contaminar o distorsionar aquello que se ve (Piñeiro y Diz, 2018). Aunque esta mirada viene influida por diversos factores, es fundamental detectarlo para poder vaciar parte de la experiencia propia y, observar al fenómeno desde una mirada menos contagiosa (Husserl, 1962).

Transgeneracional porque se centra en rescatar parte del pasado que se hereda (Feil, 2006; Lumey, 1992; Pembrey, 2002; Hellinger y Olvera, 2010). Retoma todo de lo que provenimos: historias, personas, culturas, orígenes, territorios... para poder asentir, reconocer y percibir esa fortaleza en el interior. Permite observarnos como elementos de una cadena que seguirá construyendo su futuro y de la que formaremos parte. Se trata de una mirada de acercamiento, de inclusión de historias que, gusten o no, 
forman parte del entramado que nos trae al momento presente tal y como es. Una mirada de agradecimiento al pasado para soltarlo y caminar libre hacia un nuevo futuro que deje de ser fiel y leal inconscientemente (Jung, 1970; Boszormenyi-Nagy y Spark, 2008; Hellinger, 2008; Schützenberger, 2006).

La pedagogía sistémica nos aproxima a nuestra propia historia, para reconocerla, asentirla y dignificarla. Nos aproxima a la otra persona para que podamos imaginar la historia que lleva detrás y poderle contemplar con su propia fuerza. Quizás, si conseguimos tomar consciencia y ocuparnos de parte del desastre que nos corresponde, podremos convertirnos en mejores ciudadanos para el mundo.

\subsection{Los Órdenes}

Trasladar esta mirada humana que dignifica familia y territorio, puede aproximar al autoconocimiento y al conocimiento de las demás. Esta pedagogía hace hincapié en el lugar de pertenencia de todas las personas, en el reconocimiento de funciones, en las responsabilidades de cada quien dependiendo de su lugar de pertenencia, en la compensación entre recibir y dar para el desempeño de esas responsabilidades, y en el cuidado de los vínculos que se establecen. Todo ello, se engloba en los tres órdenes: pertenencia, precedencia y compensación entre recibir y dar (Hellinger, 2001; Olvera y Bolzmann, 2007; Traveset, 2007).

Si deseamos comprender al alumnado, es imprescindible realizar esta mirada zoom. Necesitamos ampliar nuestra mirada hacia una mirada sistémica que abarque e incluya las historias del alumnado y su familia, sus experiencias, conocimientos previos, contextos, su información hereditaria (Feil, 2006; Traveset, 2007) que guía hacia un inconsciente colectivo (Jung, 1970; Hellinger, 2009). Así se tranformará hacia una mirada holística, que no entienda sobre buenos o malos, orden o desorden, partes o todo; una mirada amplia que sostenga al "sistema-entorno" (Luhmann, 1998) y a su vez lo diferencie. Una mirada que desde el antagonismo se complemente (Traveset, 2007; Morin, 2006).

\subsection{Acciones}

La pedagogía sistémica toma de los órdenes del amor una serie de acciones que promueve y al mismo tiempo se sustenta de ellas: asentir, incluir, reconocer, agradecer y honrar (Hellinger, 2001).

Asentir el presente tal y como llega es asentir al pasado tal y como fue, no se puede cambiar la historia pero sí escoger cómo deseamos vivirla de ahora en adelante. Implica asentir sucesos, emociones, creencias, espacios, tiempos, ritmos. Todo ello, puede ser de ayuda para observar qué se puede transformar porque depende de nuestra acción, y qué es mejor liberar porque no nos corresponde su solución. 
Incluir todo aquello que fue en la historia: sucesos, emociones, personas que llegaron a formar parte del sistema, aunque fuera por un corto período de tiempo. Incluir lo que me trae al presente tal y como soy. Incluir la dicotomía, existe inclusión porque hay exclusión. La exclusión es la que me muestra el camino hacia la inclusión y hace que se tome consciencia para transformar. No se puede excluir a la exclusión, sería no asentir la realidad. Desde esta mirada, la exclusión necesita su reconocimiento, pues este concepto de inclusión nos agranda el corazón, nos expande. En la escuela hay cabida para todos los sistemas familiares, todas las funciones, todas las personas que la forman, todas las culturas y territorios que conviven, el reto es enfocar hacia un mismo objetivo.

Reconocer, va más allá de un volver a conocer. Primero, se produce un acercamiento desde la mirada sistémica para conocer de cerca el suceso, emociones, las funciones, las responsabilidades... Después, aprender a valorar el lugar que ocupa cada quien. Se podría deducir que es un conocimiento hacia esa persona, acto, emoción... desde una mirada de valoración que a su vez, incluye y dignifica.

Agradecer todo aquello que nos abre paso desde aquello que suma y se valora, es parte de una filosofía de vida. Ser agradecido nos vuelve humildes, humanos y, nos acerca a la otra persona reconociendo sus actos. Agradecer a la vida, al agua, viento, sol, tierra, a los alimentos, a todas aquellas personas que hacen posible que yo esté aquí tal y como estoy, tal y como soy.

Honrar, podría incluir a todas las acciones nombradas. Desde la pedagogía sistémica puede comprenderse cómo mostrar consideración hacia las demás personas, hacia todo lo que nos rodea incluido el territorio que pisamos. Significa tomar la vida tal y como llega, con la vida y con la muerte. Reconocer desde un sentimiento profundo el derecho ancestral de cada pueblo, de cada ser. Dignificar los conocimientos que se traspasan entre generaciones desde una sabiduría colectiva ancestral enfocada al cuidado de los bosques, de la biodiversidad, del cuidado de la naturaleza de manera consciente, así como de los minerales, aguas y animales.

La delicadeza y cuidado que envuelve a la pedagogía sistémica en sus acciones, nos aproxima a una entrada al campo respetuosa. Más adelante, podremos observar si se encuentran similitudes y puntos de convergencia entre pedagogía sistémica y método etnográfico, por el momento, destacamos que la pedagogía sistémica se acerca a la mirada etnográfica que "invita a entender el "nosotros" por reflejo de los otros" (Velasco y Díaz de la Rada, 1997).

\subsection{La entrada al campo desde el método etnográfico}

Remarcamos la base que nos aporta el método etnográfico para realizar la entrada al campo y la producción de datos; a su vez la pedagogía sistémica establece una serie de indicaciones que facilitan 
la llegada al campo de una manera cuidadosa y respetuosa con el entorno al que se pretende acceder para la investigación: su forma de mirar (sistémica, fenomenológica y transgeneracional); los órdenes que ayudan a la investigadora a posicionarse en el lugar que le corresponde (pertenencia, precedencia y compensación entre recibir y dar); y las acciones (asentir, incluir, reconocer, agradecer, honrar).

Este acercamiento a la realidad social de la escuela y de su contexto (Ferrándiz, 2011) es necesario para comprender la totalidad del sistema. Desde la etnografía se hace hincapié en la consideración de la cultura como un todo, pues no se pueden aislar ciertas conductas, saberes, creencias, valores... del contexto y de su historia (Malinowski, 1995; Álvarez, 2008; Segarra, Traver y Lozano, 2015). "La etnografía de la escuela no es más que el resultado de aplicar una práctica etnográfica y una reflexión antropológica al estudio de la institución escolar” (Velasco y Díaz de Rada, 1997, p.10).

El método etnográfico nos guía en el acercamiento al territorio, en cómo realizar el estudio del contexto escolar para descubrir el conjunto de interacciones que se producen. A cómo describir la realidad de lo que allí sucede desde una mirada fenomenológica saliendo de uno mismo para comprender la cultura de la otra persona y así, comprender sus creencias, valores y formas de vida desde su propia cosmovisión (Hammersley y Atkinson, 1994; Celigueta y Solé, 2013).

El método etnográfico nos guía y describe cómo poder llevar a cabo la construcción del corpus formando parte de la vida de las personas que se desea comprender (Estalella, 2015), de manera que culmine con un relato final que permita comprender la realidad estudiada. El etnógrafo se interesa en captar el punto de vista del sujeto y la perspectiva con que éste ve a los demás (Woods, 1987), lo que nos conecta con la mirada sistémica, fenomenológica y transgeneracional en la que se sostiene la pedagogía sistémica. Presta atención a las actividades que se realizan, a la comunicación, a las diferentes creencias, valores, perspectivas de las personas que conforman la escuela y su entorno.

Se irá relatando una manera de hacer que se incluye dentro de la pedagogía sistémica. No será necesario seguir forzosamente los pasos que mencionaremos, aunque dichos pasos pueden encaminarnos hacia una mirada sistémica ante la vida, más allá de la propia investigación.

\section{Metodología}

Se trata de una investigación cualitativa, un estudio de caso desde la etnografía. La investigación a la que pertenece esta entrada al campo se centra en el estudio de las relaciones de convivencias en un centro escolar y su contexto. Sin embargo, el objetivo del artículo se focaliza únicamente en describir el proceso de llegada al campo para analizar las sinergias entre la puesta en práctica de la pedagogía sistémica y el método etnográfico durante el comienzo de la investigación desde la visión de la investigadora. 
Todo ello, se desarrolla en el Centro Rural Agrupado Peña Escabia (en adelante CRA), situado en el interior de la provincia de Castellón, comarca del Alto Palancia. Su situación geográfica y climática lo ubica en un entorno que puede resultar inaccesible en días de invierno. Lo forman cinco pueblos que limitan con las provincias de Teruel y Valencia: Bejís, Teresa, Torás, Barracas y El Toro.

El claustro demandó un taller de iniciación en pedagogía sistémica. La coordinadora de formación buscaba una persona que pudiera facilitar dicho taller y acceder con facilidad al CRA, pues su situación geográfica dificulta sus formaciones, no todas las personas están dispuestas a asistir debido a la lejanía.

Esta demanda inicial del taller y los intereses de la investigadora por desarrollarlo en la comarca de la cual es originaria, posibilitaron el desarrollo de la investigación y por consiguiente, de la entrada al campo a la que se hace referencia. Ésta tuvo una duración de aproximadamente tres meses.

Durante este tiempo, la técnica para producir datos fue la observación participante (Jociles, 2017), participando en la vida comunitaria y observando lo que sucede en el entorno (Guerrero, Ferraro y Hermosa, 2016) a través del diario de campo, utilizando el cuaderno y la grabadora de voz. Los informantes durante el proceso de la entrada al campo fueron el claustro y las familias. Sin embargo, debido a que se relata la entrada al campo y, no se tienen todavía los consentimientos informados, todo el relato se basa en el enfoque de la investigadora desde el diario de campo.

Desde la toma de contacto, se describió cada paso realizado en el diario de campo. Se recogieron frases y conversaciones casuales surgidas entre pasillos, en la calle, con vecinos... Reflexiones, observaciones, pensamientos o hechos vividos durante el proceso de entrada, personales de la investigadora, hacia los participantes y hacia el entorno. Todo ello, le servía a la investigadora para encontrar su lugar durante la entrada al campo e ir comprendiendo el contexto, no tanto como producción de datos para el análisis de la investigación.

Aunque desde los resultados se mencione la realización de entrevistas iniciales o reparto de formularios, estas técnicas no se especifican en la metodología porque dichos resultados no están relacionados con la entrada al campo o con las sinergias que se desean mostrar, sino con las relaciones de convivencia, tema central de la investigación. Lo que se desea destacar en resultados, es el protocolo seguido y la forma cuidadosa en la que estas técnicas fueron introducidas y empleadas.

Los datos analizados para observar estas sinergias se produjeron, como se ha mencionado, desde la observación participante. Los datos que se produjeron desde el inicio mencionaban la forma de aproximarse al territorio por parte de la investigadora. La fase de reflexión de análisis de contenido (Vázquez, 1996) se realizaba al llegar a casa, consistía en revisar los pasos y el acercamiento en cada uno de los aularios de los cinco municipios, esta triangulación de datos producidos en los diferentes momentos y espacios (Angrosino, 2017), aportaba nuevas ideas para regresar al campo y establecer contactos. 
Sobre cuestiones éticas, veremos en el relato cómo aunque se otorgó el permiso para la investigación desde el equipo directivo, se acordó redactar una circular informativa donde se invitaba a las familias, personal docente y no docente, a asistir a la presentación de la investigación para que conocieran los propósitos de la misma y participasen aquellas personas que desearan. El la circular se especificaban los propósitos de vínculo con su territorio, con sus orígenes y con la escuela.

Como limitaciones del método podríamos señalar que, la investigación etnográfica podría producir otros datos dependiendo de los intereses de la investigadora (Angrosino, 2017). Debido a cuestiones propias del contexto y del deseo de la investigadora por respetar esos ritmos, la investigación fue más pausada y se necesitó más tiempo del planificado. Por ello, se consideró la duración de la entrada de aproximadamente tres meses. La referencia entre el inicio y el final de la entrada se marcó desde el primer contacto de demanda del claustro hasta el comienzo del taller con las familias, éste comenzó más tarde debido a la dificultad para los encuentros con las familias de los cinco pueblos.

\section{Resultados}

Se relata cómo se realizó la entrada al campo describiendo los pasos y acciones desde la sistémica y la etnografía para finalmente, entender las sinergias entre ambas y cómo estas pueden dar lugar a una investigación cuidadosa hacia las personas y hacia el medio.

\subsection{Primer paso. La demanda y posicionamiento}

La realización del taller junto con la investigación que la engloba partió de dos demandas. Por un lado, la investigadora deseaba encontrar una escuela próxima a su territorio de origen que deseara participar en la investigación relacionada con la pedagogía sistémica. Por otro, la escuela deseaba una formación en pedagogía sistémica.

Respetar el momento de demanda fue, desde la mirada sistémica, colocarse en el lugar correspondiente, así se partía de la necesidad del propio centro y no de un interés personal que empujaba. Se requirió paciencia, hubiera resultado contraproducente animar a un grupo a que realizara una formación sin que hubiese encontrado su necesidad personal y grupal.

Por ello, es necesario asegurarse de una posición de igual a igual, así quien facilita se aleja de una posición que, inconscientemente, le colocaría en un nivel superior: yo te doy lo que veo que necesitas.

Este movimiento guiaba a la investigadora hacia otro posicionamiento, el de colocarse como facilitadora del proceso contemplando la fuerza que habita en dicho sistema que pide apoyo. Observando esa 
fuerza, la investigadora veía al grupo como igual y no como algo pequeño que necesitaba ayuda. Desde esta mirada sistémica, quienes facilitan evitan situarse como padres de la escuela.

Una vez establecida la demanda, antes del acercamiento al CRA para la entrada al campo, estos fueron los pasos que se tomaron desde casa:

- Visualizar las posibles fortalezas del CRA (incluía a las familias, alumnado, personal docente, no docente, sus sistemas de familiares, ayuntamientos, territorio...)

- Buscar documentación (histórica, geográfica, económica, climática...) acerca de los pueblos del CRA y su entorno

- Conectar con la mirada transgeneracional para dignificar territorios y culturas de la zona

- Reconocer las funciones y personas que hacen posible el funcionamiento del CRA

- Reconocer a las familias como responsables de la educación de sus hijos

- Reconocer a los docentes por su labor al servicio de la sociedad

\subsection{Segundo paso. Fase 1 de negociación: Primera visita al campo.}

La demanda del taller supuso el primer paso para la investigación, sin embargo, seguía siendo una incertidumbre. Para su puesta en marcha era necesario presentar el proyecto a la comunidad escolar y pedirles permiso.

Mantener la mirada en la pedagogía sistémica servía de recordatorio para continuar en la posición correspondiente como facilitadora del taller, observadora participante e investigadora. Para ello, los órdenes del amor ayudaron a la investigadora a mantener su lugar de correspondencia. El primero paso, fue el acercamiento al equipo directivo para exponer la propuesta. Se concertó una reunión entre el equipo directivo, la coordinadora de formación y la investigadora para detallar el enfoque, metodología y contenido del taller que era lo que ellos demandaban y; presentarles el proyecto de investigación, que era la demanda de la investigadora. Se comprobaría si realmente ambos proyectos se ajustaban a ambas demandas.

Una vez se llegó a Bejís (sede del equipo directivo), la investigadora recordó todos los pasos previos para reconocerlos y hacerles un lugar en el corazón. Se detallan como ejemplo de mirada sistémica.

He llegado a la primera rotonda del pueblo, una gota de agua convertida en estatuilla abre paso en primer plano. Bajo las ventanillas del coche, respiro agradeciendo por ese instante que me trae aquí. Por cada 
paso dado... me siento enormemente agradecida, satisfecha por el simple hecho de haber llegado hasta aquí sin expectativas. Agradeciendo todo lo que abarca mi mirada. De forma simbólica miro al pueblo mientras me adentro y digo: Gracias Bejís por acogerme, te pido permiso para hacer este trabajo. (Extraído del diario de campo)

A continuación, se muestra un fragmento del diario donde se secuencian los pasos seguidos por la investigadora en el momento de aproximación al campo. Reflejan la puesta en práctica de la mirada sistémica:

- Agradecer mi vida y mi sistema familiar.

- Agradecer a todas las personas que me han traído hasta aquí, formaciones recibidas, y experiencias vividas.

- Agradecer al pueblo que me acoge, a la escuela y a las personas que me invitan.

- Reconocer a los sistemas familiares de las personas con las que tengo el encuentro y visibilizar sus fortalezas para situarme de igual a igual.

- Visualizar a las familias, al alumnado y al resto de personal docente y no docente para incluirlos desde mi corazón.

- Visualizar el objetivo de la escuela en el mayor beneficio.

- Escuchar su demanda y sus necesidades previas, sin juicios, sin interpretaciones.

- Realizar la propuesta de investigación.

- Pedir permiso para invitar a las personas que conforman la escuela con el fin de darles a conocer el proceso que se va a desarrollar con el claustro e invitarles a participar si lo desean.

- Pedir permiso para la realización formal de la investigación. (Extraído del diario de campo)

\subsection{Tercer paso. Fase 2 de negociación: La presentación en la comunidad}

Acordado el inicio del taller con el claustro y recibido el consentimiento para la investigación por parte del equipo directivo, se pasó a la presentación del proyecto a la comunidad escolar. La respuesta que tendrían las familias respecto a la participación en el taller y a la investigación seguía siendo desconocida. La mirada sistémica como investigadora, la pedagogía sistémica como contenido de formación 
desde el posicionamiento de facilitadora y, la ética del método etnográfico, situaban a la investigadora en un lugar donde pedir permiso para la investigación era imprescindible. Aunque el equipo directivo se mostró dispuesto a dar paso, se deseaba contemplar al conjunto de la comunidad para acercarse a ella con el debido respeto y detallarles el proceso. No podía saltarse el lugar de las familias y realizar algo en la escuela únicamente desde el consentimiento del equipo docente (Piñeiro y Diz, 2018).

Esta fase, obligada y crucial para la investigación, determinaría el curso de la misma.

En la presentación del proyecto, la mirada sistémica llevó a realizar las siguientes acciones:

- Llegar con antelación a la sala para la preparación y acogida de las personas asistentes.

- Agradecer la sala que acoge, agradecer lo que hace posible estar ahí.

- Agradecer a las personas del equipo docente que ofrecieron su ayuda para la instalación del equipo tecnológico.

- Agradecer al territorio.

- Colocar las sillas en semi-círculo para que resultara un espacio más cálido y familiar.

- Visibilizar los 5 pueblos y sus gentes, honrando lo rural.

- Respirar y conectarse con las posibles situaciones que se viven en el contexto para iniciar un diálogo desde la cercanía. (Extraído del diario de campo)

Comenzaron a llegar las asistentes, todas mujeres, fueron ocupando sus lugares; en representación masculina había un maestro. En ese momento, la mente de la investigadora se dirigió hacia los hombres para darles un lugar de pertenencia desde su corazón, imaginando su presencia. Cada padre con rostro desconocido, al lado de cada madre que veía. También imaginó más familias que no llegaron. Las madres y abuela que asistieron se situaron en las sillas preparadas, el equipo docente decidió quedarse detrás del todo. Esa forma de colocarse, aunque fuera inconsciente, leída desde la mirada sistémica tenía mucha fuerza: las familias al frente, en primera fila, tomando las riendas de la educación de sus hijos; el equipo docente detrás, dejando el primer lugar a las familias, colocándose como apoyo secundario y no como único responsable. Esta imagen sirvió como ejemplo para el diálogo de presentación.

Para la investigadora, la simple asistencia a la reunión, que según el equipo docente fue numerosa; era el paso inicial de acercamiento. Que estuviesen allí significaba decir sí a la invitación y, sí al deseo de mirar hacia el vínculo con su territorio, con sus orígenes y con la escuela. 
Al finalizar la reunión algunas madres se acercaron para asentir a la participación del taller y pedir si se podría repetir la presentación en Barracas, por lo que se interpretó que la presentación les interesó y motivó.

- Esto que has hecho, ¿podrías repetirlo en Barracas para otras madres que no han podido venir?

- Sí, porque les gustaría - dijo otra madre (Extraído del diario de campo)

Y así se hizo, días más tarde, de la misma forma.

En esta presentación de Bejís, a sorpresa para todas, la investigadora encontró tres caras conocidas entre el claustro y familias. Este detalle hizo que fueran ellas las primeras personas con las que más adelante, se acercaría para comenzar con la producción de datos en relación a la investigación. De esta forma, conseguiría soltura ante la entrevista que había preparado y podría detectar posibles errores en las preguntas, sería muy cómodo para ambas partes por la relación de cercanía.

Estos encuentros fueron girando en espiral, conforme se fueron conociendo más de cerca a las madres que se pusieron en contacto por su deseo de participar en el taller, se frecuentó con más asiduidad las escuelas en horario de salida del alumnado con el fin de ir creando confianza y visibilidad. De esta forma, se pudo entablar más conversaciones y el círculo de conocidos se fue ampliando. Se decidió esperar desde la calma el momento oportuno para la producción de ciertos datos porque todavía se debían firmar los permisos. Sin embargo, se reflejaban todos los pasos en el diario de campo.

El ritmo que se marcaba hacia la investigación desde fuera, no correspondía con el ritmo de la comunidad y del trabajo en el campo. "Todo a su ritmo y a su tiempo" es una frase que recordaba la conveniencia de no apresurarse para evitar que la desconfianza frenase después la disponibilidad y participación.

Debido a los horarios laborales de las familias y otras ocupaciones del hogar fue complejo calendarizar el taller. El personal no docente no podría asistir al taller debido al horario que finalmente se estableció con las familias. De las catorce familias que mostraron interés, podrían participar siete. El claustro participaría al completo.

\subsection{Cuarto paso. Fase 3 de negociación: Consentimiento informado}

Se confeccionaron las dos listas de participantes por parte del claustro y familias. Se dio paso a la firma de documentos para obtener los permisos oportunos que abrían el procedimiento de la investigación y se organizó el calendario para establecer las ochos sesiones de taller con cada grupo.

Se elaboró un formulario inicial para identificar las motivaciones y necesidades de participación en el taller en relación a la mejora de la convivencia en la comunidad escolar. Todo ello, sirvió para adaptar parte del taller a sus necesidades. 


\subsection{Quinto paso. Final del proceso de entrada al campo}

En esta fase de cierre de la entrada al campo, la investigadora necesitó recalibrar su lugar de pertenencia respetando los órdenes del amor para abrir paso a la investigación. Tuvo en cuenta que ella llegó en último lugar al CRA; desde ahí observó y reconoció al alumnado, a sus familias, a la trayectoria de cada docente, sus funciones y las del personal no docente.

Por otro lado, debía cerciorarse de qué lugar ocuparía en cada una de las tres posiciones: como facilitadora del taller, como observadora participante y como investigadora.

Tras el final de la entrada al campo, la actividad investigadora se inició respetando el orden de llegada al sistema. Primero comenzó la observación participante con el equipo docente porque fue este quien le contactó, en aquellos lugares en los que creyeron oportunos. Aun con la inquietud por investigar, sabía que llegaba en último lugar al CRA y que debía adaptarse a los ritmos y espacios marcados. Aunque estaba en primer lugar como responsable de la investigación, contemplando el sistema escolar al completo, la investigadora quedaba al servicio de este junto con la investigación.

Se dio por finalizada la entrada al campo cuando se aseguró que todas las familias sabían del comienzo del taller. En este momento se abrió paso a otro proceso, dando por concluida la toma de contacto y entrada al campo.

Para finalizar, en la figura 1 se muestra la aportación que realiza la pedagogía sistémica en la entrada al campo de investigación y cómo puede converger con las aportaciones del método etnográfico.

\begin{tabular}{|l|l|}
\hline \multicolumn{1}{|c|}{ MIRADA SISTÉMICA } & \multicolumn{1}{c|}{ MÉTODO ETNOGRÁFICO } \\
\hline $\begin{array}{l}\text { Forma de comprender la realidad social a través de } \\
\text { ampliar la mirada hacia lo sistémico, transgenera- } \\
\text { cional, fenomenológico, emocional }\end{array}$ & $\begin{array}{l}\text { Forma de comprender la realidad social a } \\
\text { través del proceso de investigación. Mirada } \\
\text { fenomenológica }\end{array}$ \\
\hline $\begin{array}{l}\text { Necesidad de respetar los órdenes del amor, para } \\
\text { encontrar nuestra posición y pedir permisos de } \\
\text { manera ética, responsable, agradecida y respetuosa } \\
\text { con las personas informantes. }\end{array}$ & $\begin{array}{l}\text { Necesidad de consentimiento informado para la } \\
\text { protección de datos de las personas participan- } \\
\text { tes y para no invadir aquellos espacios que no } \\
\text { nos corresponden, establecer los acuerdos de } \\
\text { actuación. }\end{array}$ \\
\hline $\begin{array}{l}\text { Los órdenes del amor: pertenencia, precedencia y } \\
\text { compensación, pueden facilitar el posicionamiento } \\
\text { de la investigadora en el campo. }\end{array}$ & $\begin{array}{l}\text { Fases y etapas de investigación, posicionamien- } \\
\text { to etnográfico en cuanto a la entrada al campo, } \\
\text { trabajo y salida del mismo } \\
\text { Posición de extrañamiento } \\
\text { Posición de observador participante } \\
\text { Posición de analizar y relatar fenomenológica }\end{array}$ \\
\hline
\end{tabular}




\begin{tabular}{|l|l|}
\hline $\begin{array}{l}\text { A pesar de todos los estudios realizados, resulta ser } \\
\text { un campo todavía de escasa investigación cientí- } \\
\text { fica y no es un método de investigación científica } \\
\text { como tal. }\end{array}$ & $\begin{array}{l}\text { Ofrece un campo fundamentado científicamen- } \\
\text { te en el que apoyarse. Es un campo robusto con } \\
\text { muchas experiencias en investigación. }\end{array}$ \\
\hline $\begin{array}{l}\text { Despierta un interés hacia sus propios orígenes y } \\
\text { sistemas (persona, familia, cultura, territorio) para } \\
\text { reconocerlo con dignidad. Expande ese sentimien- } \\
\text { to de reconocimiento y dignidad hacia los orígenes } \\
\begin{array}{l}\text { y sistemas (persona, familia, cultura, territorio) de } \\
\text { las otras personas }\end{array}\end{array}$ & $\begin{array}{l}\text { Despierta interés en cómo se realiza la produc- } \\
\text { ción de datos para cerciorarse que se obtiene } \\
\text { la información precisa que describe la realidad } \\
\text { observada (desde diferentes miradas, técnicas, } \\
\text { momentos) de la manera más fenomenológica } \\
\text { posible. Procedimiento que nos asegura que la } \\
\text { producción de datos es válida y fiable. }\end{array}$ \\
\hline $\begin{array}{l}\text { Insistencia en realizar un trabajo etnográfico cau- } \\
\text { teloso para acercarse a la otra cultura y a cualquier } \\
\text { ser desde acciones que promueve. (asentir, incluir, } \\
\text { agradecer, reconocer, honrar) }\end{array}$ & $\begin{array}{l}\text { Guía para desarrollar el proceso de investiga- } \\
\text { ción y para describir la realidad a estudiar o } \\
\text { comprender. }\end{array}$ \\
\hline $\begin{array}{l}\text { Nos dirige hacia un método etnográfico que puede } \\
\text { fundamentar la investigación en pedagogía sistémi- } \\
\text { ca, debido al interés que despierta hacia el estudio } \\
\text { de otras culturas, hacia el conocimiento y recono- } \\
\text { cimiento de la historia personal y de la historia de } \\
\text { otras personas con las que se relaciona. }\end{array}$ & $\begin{array}{l}\text { Nos puede dirigir hacia la pedagogía sistémica } \\
\text { en cuanto a lo que esta podría aportar (mirada } \\
\text { sistémica, órdenes, acciones) en algunos pasos } \\
\text { del proceso etnográfico profundizando en } \\
\text { aspectos de sensibilidad y humildad. }\end{array}$ \\
\hline
\end{tabular}

Figura 1. Aportaciones y sinergias entre pedagogía sistémica y método etnográfico. Elaboración propia.

\section{Discusión y conclusiones}

La mirada sistémica en la investigación etnográfica educativa nos permite contemplar a la escuela desde otra perspectiva que implica: Abrirnos a su pasado histórico, a su territorio, sus culturas, a la fuerza de las familias, alumnado, personal docente, no docente... Asentir su situación presente incluyendo lo que la hace tal y como es. Agradecer la posibilidad de aprender junto a ellos. Reconocer sus fortalezas. Honrar su sabiduría (Hellinger y Olvera, 2010; Fontes, 2008).

Tener presente esta mirada sistémica implica pedir permiso a toda la comunidad (Guerero, Ferraro y Hermosa, 2016), según Stake (1999:58): “Casi siempre, la recogida de datos se "juega en casa” de alguien", la investigación conlleva a una invasión en la vida privada escolar y por tanto familiar.

Como vimos, los consentimientos firmados no otorgaban vía libre, ni colocaban a la investigadora en un lugar desde el que pudiera acampar a sus anchas por la escuela, invadiendo espacios y vidas personales de equipo docente, alumnado y familias. La participación y observación en el campo requería de un movimiento cuidadoso con el entorno que se ofrecía voluntariamente a la investigación. La pedagogía sistémica facilitó el lugar de pertenencia de la investigadora. 
Es necesario que la obtención de permisos no se convierta en un cúmulo de papeles con firmas que finalicen desconsiderando los aspectos morales de la situación. Los permisos deben enfocar más allá de la situación burocrática y centrarse en el respeto hacia las personas que van a participar (Stake, 1999); alejándose de un ímpetu por investigar que hace que se olviden ciertas pautas de actuación que quedan lejos del reconocimiento.

Autores como Woods (1987) observan el proceso desde la siguiente perspectiva: «en el fondo, se trata de venderse a sí mismo como una persona digna de crédito que lleva a cabo un proyecto de valor» (p.37). Desde la mirada sistémica se amplía esta idea, si se tratase de venderse como expertos, nos podríamos dar de bruces más adelante, para mantener la investigación no solamente se necesita el consentimiento informado, sino una serie de valores con los que se pueda convivir mientras esta continúe. En este caso, para poder mirar la pedagogía sistémica en su complejidad y su completitud, fue necesario el deseo de mirar por parte del equipo docente y de las familias.

Por otro lado, cuando las personas se sienten respetadas en sus tiempos y espacios y reconocidas en sus funciones, es probable que puedan mostrar interés en la participación de la investigación cuando esta les dignifica y honra (Hellinger, 2008; Álvarez, 2017; Pastor, 2006), de esta manera se alejan de ser simples sujetos de estudio (Guerrero, Ferraro y Hermosa, 2016).

En cuanto a la forma de posicionarse decir que, como observadora participante, debía ser una más procurando interferir lo menos posible en la vida de las personas participantes. Como investigadora, debía de tomar ciertas distancias para observar los fenómenos desde una posición de extrañamiento (Hammersley y Atkinson, 1994; Malinowski, 1995; Velasco y Díaz de Rada, 1997) que danzaba entre el despacho y el campo (Álvarez, 2008). Como facilitadora, debía sostener el taller, aquí la investigadora tomaba las riendas del mismo siendo su responsabilidad, debía transmitir el contenido del curso mientras observaba cómo se podían respetar los órdenes del amor en el grupo durante este espacio-tiempo.

Acercarse a la etnografía como método de entrada al campo, registro de observaciones y producción de datos, fue otra pieza clave para dar comienzo al taller, pues antes de que éste iniciase, se pudo observar parte del contexto que envolvía al CRA. Ello le ayudó a saber cómo dar inicio al taller y qué necesidades tenían para poder acomodar el contenido del taller a sus inquietudes.

Desde la observación participante existe un intercambio de información bidireccional, no solamente se tiene en cuenta las figuras investigador-investigado, sino que se crea un vínculo de compensación donde ambas personas aportan y ambas personas aprenden. Desde este punto de vista, la información que se produce es fruto de las relaciones de confianza que se establecen y todo lo que llegue será bien recibido desde el agradecimiento y no desde una búsqueda de información en la que las personas se sientan obligadas a ofrecerla (Velasco y Díaz de Rada, 1997). Debido a esto y a los órdenes de la pedagogía 
sistémica se antepuso respetar los ritmos de los participantes para conocerse, pues se pretendía evitar que ellos se adaptaran a la tesis.

Poner en práctica la mirada sistémica, aportó capacidad de adaptación y observación para obtener información de una forma cuidadosa y respetuosa alejada de la intromisión (Velasco y Díaz de Rada, 1997) y así, respetar los órdenes de llegada de la pedagogía sistémica (Hellinger, 2001). Todo ello, aseguraba un proceso de respeto, armonía y de orden en el sistema.

Puesto que, como comenta Álvarez (2008) "el ingreso en el campo de estudio suele ser un problema al que aluden todas las obras sobre etnografía" (p.90). La pedagogía sistémica puede complementar esta parte de la etnografía aportando su mirada, pues si bien ésta no pretende asegurar la apertura de puertas al campo de estudio, sí asegura respeto, dignificación, cuidado y reconocimiento al lugar de emplazamiento. La mirada sistémica en la etnografía educativa puede facilitar a la persona que investiga en ciertos aspectos. Puede ayudarle a comprender cuál es su lugar de pertenencia en el campo; cuándo y dónde ubicarse desde sus responsabilidades para no inmiscuirse en asuntos que son competencia exclusiva de la escuela (Hellinger, 2001; Parellada, 2006; Pastor, 2006; Olvera y Bolzmann, 2007). Puede ayudarle a pedir permisos correspondientes y establecer los aspectos prioritarios. Por ejemplo, para acceder al alumnado, es fundamental contar con el consentimiento previo de las familias. Si bien no se establece un requisito formal desde la institución, existe un deber ético que hace que no nos saltemos a los padres.

Como observamos, la etnografía puede convertirse en un proceso de espiral, pudiendo dar inicio a procesos de retorno dentro del mismo (Aguirre, 2016), resultando complejo delimitar cuándo empieza y cuándo acaba. Desde un inicio la producción de datos y su análisis fue primordial para encaminarnos hacia próximos pasos, por ello se dice que se trata de un proceso cíclico (Woods, 1987; Del Rincón 1997; Álvarez, 2008; Ballesteros, et al., 2014; Sánchez y Estalella, 2016). No obstante, todo proceso pasa por las siguientes fases o etapas: el plan de diseño y la revisión de bibliografía; la entrada al campo, el trabajo en el emplazamiento y la salida del mismo; análisis de datos donde se interpretan, triangulan y validan; y la redacción del informe final (Aguirre, 2016).

Desde aquí, hacemos referencia únicamente a la segunda fase que es en la que nos hemos centrado en este artículo para la descripción de la entrada al campo. Sin embargo, nos daremos cuenta que como proceso etnográfico, la redacción de este artículo también pasó, de alguna forma, por las cuatro fases nombradas.

En la segunda fase es en la que se sitúa la entrada al campo, se produce la toma de contacto con el contexto de estudio, se establecen las negociaciones y presentaciones. En esta fase ya se dio comienzo a la producción de datos desde el inicio, pues desde la primera toma de contacto se utilizó el diario de campo que sirvió como aproximación al contexto (Sanchiz y Cantón, 1995). 
Se observó cómo con la aparición en diversos contextos, la observación participante, la paciencia y discreción (Sanmartín, 2000; Woods, 1987), se pudo crear un vínculo de confianza que dio pie a procesos posteriores de producción de datos. Entre estas fases se produjo el proceso cíclico combinando idas y vueltas al campo de estudio con lo cual, saber qué posición adoptar en cada momento fue fundamental. La pedagogía sistémica nos ayudó a establecer el lugar de pertenencia que nos correspondía en cada una de las fases.

La entrada al campo también sirvió para aproximarnos a la escuela (familia, alumnado, docente, equipo no docente) y territorio que lo engloba aportando información (Sanchiz y Cantón, 1995). Llevar a cabo una aproximación al contexto donde se iba a realizar el taller fue fundamental para establecer el contenido y la forma en la que éste se presentaría en relación a sus necesidades internas. Dichas bases de acercamiento entre la investigadora y el contexto no solamente las pautaba el método etnográfico, sino que la pedagogía sistémica también pudo guiarnos durante este proceso que se consideró respetuoso (Álvarez, 2017), lo que puede servir de ayuda a futuros investigadores, facilitadores y también a personal docente para conocer y dignificar a su alumnado, familiares y al territorio donde se trabaja.

\section{REFERENCIAS}

Aguirre, A. (2016). Ciudades de papel. Etnografía militante sobre la cultura de participación juvenil en la casa de joventut La Maranya. (Tesis doctoral). Castellón: Universitat Jaume I

Álvarez, C. (2008). La etnografía como modelo de investigación en educación. Gazeta de Antropología 24 (1), 1-15. Recuperado de http://hdl.handle.net/10481/6998

Álvarez, Q. (2017). Pedagogía sistémica e interculturalidad: claves para construir un aula inclusiva Revista Lusófona de Educação, (37), 165-179

Ander-Egg, E. (1996). La planificación educativa. Conceptos, métodos, estrategias y técnicas para educadores. Buenos Aires: Magisterio

Angrosino, M. (2017). Etnografía y observación participante en Investigación Cualitativa. Madrid: Morata

Ballesteros, B. y Mata, P. (2014). Sentido y forma de la investigación cualitativa. En B. Ballesteros (Ed.), Taller de investigación cualitativa (pp.11-46). Madrid, España: UNED.

Bertalanffy, L. (1989). Teoría general de los sistemas. Fundamentos, desarrollo, aplicaciones. México: Fondo de Cultura Económica. 
Boszormenyi-Nagy, I. y Spark, G.M. (2008). Lealtades invisibles. Reciprocidad en terapia familiar intergeneracional. Madrid: Amorrortu

Bronfenbrenner, U. (1987). La ecología del desarrollo humano. Cognición y desarrollo humano. Barcelona: Paidós.

Celigueta, G. y Solé, J. (2013). Etnografía para educadores. Barcelona: UOC.

Del Rincón, D. (1997). La metodología cualitativa orientada a la comprensión. Barcelona: EDIOUC

Edgerton, E y Lagness, R. (1977). Method and Style in the Study of Culture. San Francisco: Chandler y Sharp.

Estalella, A. (2015). Etnografía: Observación participantes y diario de campo. CCCDES. Charlas auditorio Medialab Prado: Madrid. Recuperado de http://bit.ly/2W7GrqN

Feil, R. (2006). Environment and nutritional efects on the epigenetic regulation of genes. Mutation Research, 600(1-2), 46-57. Recuperado de http://bit.ly/2VXNjvp

Ferrándiz, F. (2011). Etnografías contemporáneas. Anclajes, métodos y claves para el futuro. Barcelona: Anthropos

Fontes, A. (2008). Manual Desarrollo Comunicario Integrativo con el enfoque de constelaciones familiars y técnicas complementarias para la salud. (Tesis posgrado). Mexico: Universidad Chapingo

Gómez, F. y Pérez, A.M. (2005). Investigación sobre la aplicación del método de las constelaciones familiares de Bert Hellinger a la supervisión clínica. Revista de investigación en psicología, 8(1), 29-50. Recuperado de http://bit.ly/2JWQufE

Gómez, F. (2007). Intervención social con familias. Madrid: Mc Graw Hill.

González, A.M. (2009). Educación holística: La pedagogía del Siglo XXI. Barcelona: Kairós.

Guerrero, P., Ferraro, E. y Hermosa, H. (2016). El trabajo antropológico. Miradas teóricas, metodológicas, etnográficas y experiencias desde la vida. Quito: Abya-Yala. Recuperado de http://bit.ly/2VVv5L6

Hammersley, M. y Atkinson, P. (1994). Etnografía. Métodos de investigación. Barcelona: Paidós.

Hellinger, B. (2001). Los órdenes del amor. Barcelona: Herder. 
Hellinger, B. (2008). Mística cotidiana. Buenos Aires: Alma Lepik.

Hellinger, B. (2009). El inconsciente colectivo y las Constelaciones Familiares. CIC. Cuadernos de Información y Comunicación, (14), 83-88. Recuperado de http://bit.ly/2QjNStE

Hellinger, B. y Olvera, A. (2010). Inteligencia Transgeneracional. México: CUDEC

Husserl, E. (1962). Ideas relativas a una fenomenología pura y una filosofía fenomenológica. México: Fondo de Cultura Económica

Jociles, M.I. (2018). La observación participante en el estudio etnográfico de las prácticas sociales. Revista colombiana de antropología, 54(1), 121-150.

Jung, C.G. (1970). Arquetipos e inconsciente colectivo. Barcelona: Paidós

Luhmann, N. (1998). Sistemas Sociales: lineamientos para una teoría general. Barcelona: Anthropos.

Lumey, L.H. (1992). Decreased birthweights in infants after maternal in utero exposure to the Dutch famine of 1944-1945. Paediatric Perinatal Epidemiology, 6(2), 240-253. Recuperado de http://bit.ly/2VCWn41

Malinowski, B. (1995). Los argonautas del Pacífico Occidental. Barcelona: Península

Maturana, H. y Varela F. (2003). El árbol del conocimiento. Las bases biológicas del entendimiento humano. Buenos Aires: Lumen

Morin, E. (2006). El Método 1: La naturaleza de la Naturaleza. Madrid: Cátedra

Olvera, A. y Scheneider, S. (2007). Los conflictos de los alumnos en la escuela como una expresión de amor a su familia. Aula de Innovación Educativa, (158), 15-17.

Olvera, A. y Bolzmann, T. (2007). La manzana no cae lejos del tronco. Aula de Innovación educative, (158), 8-10.

Parellada, C. (2006). Un nuevo paradigma educativo. Cuadernos de pedagogía, (360), 54-60.

Pastor, A. (2006). Actitudes para pensar, sentir y actuar de una forma sistémica. Cuadernos de Pedagogía, (360), 76-79.

Pembrey, M.E. (2002). Time to take epigenetic inheritance seriously. European Journal of Human Genetics, (10), 669 - 671. doi:10.1038/sj.ejhg.5200901 
Piñeiro, E. y Diz, C. (2018). El trabajo de campo como abandono: una reflexión sobre la metodología de la observación participante. Revista colombiana de antropología, 54(1), 59-88.

Sánchez Alba, B. (2013). Cooperación internacional, intercultural y educación para la paz desde un nuevo paradigma sistémico a partir del programa un mundo teñido de paz. (Tesis doctoral). Madrid: Universidad Complutense.

Sánchez, T. y Estalella, A. (Eds.) (2016). Experimental collaborations: Ethnography through Fieldwork Devices. London: Berghahn.

Sanchiz P. y Cantón, M. (1995). Acceso y adaptación al campo. En A. Aguirre (Ed.), Etnografía. Metodología cualitativa en la investigación sociocultural (pp.128-134). Barcelona, España: Marcombo

Sanmartín, R. (2000). Etnografía de los valores. Revista Teoría de la educación, (12), 129-141.

Segarra, T., Traver, J.A. y Lozano, M. (2015). Revista de currículum y formación del profesorado, 19(2), 165-183.

Schützenberger, A. (2006). ¡Ay, mis ancestros! Buenos Aires: Omeba

Stake, R.E. (1999). Investigación con estudio de casos. Madrid: Ediciones Morata

Traveset, M. (2007). La pedagogía sistémica. Fundamentos y práctica. Barcelona: Graó.

Traveset, M. (2012). Educación emocional sistémica. Herramientas para formadores, maestros y educadores. México: CUDEC®.

Vázquez, F. (1996). El análisis de contenido temático. Objetivos y medios en la investigación psicosocial. (Documento de trabajo). (pp. 47-70). Universitat Autònoma de Barcelona

Velasco, H. y Díaz de la Rada, Á. (1997). La lógica de la investigación etnográfica. Madrid: Trotta.

Woods, P. (1987). La escuela por dentro. La etnografía en la investigación educativa. Barcelona: Paidós. 